\title{
Membranas de polisulfona/argila: influência de diferentes argilas na propriedade de barreira
}

\author{
Membranes of polysulfone/clay: \\ influence of different clays on \\ the barrier property
}

\author{
Paulo Mendel Fernandes ${ }^{1}$, Keila Machado de Medeiros ${ }^{1}$, \\ Edcleide Maria Araújo ${ }^{1}$, Bruna Aline Araujo ${ }^{1}$, \\ Edson Antonio dos Santos Filho
}

Unidade Acadêmica de Engenharia de Materiais - UAEMa/CCT/UFCG - CEP: 58.429-900, Campina Grande - PB, e-mail: paulomende1000@gmail.com; keilamachadodemedeiros@gmail.com; edcleide.araujo@ufcg.edu.br; brunaline15@hotmail.com; edson.a.santos.f@gmail.com

\section{RESUMO}

Neste trabalho, membranas de polisulfona com adição de $3 \%$ em massa de argila montmorilonita natural, sódica e lítio, oriundas do estado da Paraíba, foram desenvolvidas pelo método de inversão de fases. Utilizou-se o N-metil-2 pirrolidona (NMP) como solvente na proporção de $80 \%$ e $20 \%$ de sólido. As argilas e membranas foram caracterizadas por difração de raios-X (DRX) e espectroscopia na região do infravermelho com transformada de Fourier (FTIR). Além disso, as membranas foram estudadas por microscopia eletrônica de varredura (MEV), porosidade e permeação a vapor d'água, a fim de se estudar seu comportamento para aplicação na separação de gás. Os DRX das argilas evidenciaram bandas de cristalinidade características de montmorilonita. Os difratogramas de DRX das membranas indicaram que possivelmente ocorreu a formação de uma estrutura intercalado/esfoliado devido à ausência das bandas referentes às argilas. Por FTIR das argilas foi visualizado as mesmas bandas características da montmorilonita, diferenciando pelos cátions que foram trocados na estrutura. O FTIR das membranas apresentaram bandas características da polisulfona, e para os híbridos estas bandas podem ser também das argilas por apresentarem as mesmas faixas de número de onda. As fotomicrografias de MEV evidenciaram a formação de uma camada densa na pele filtrante e na parte inferior foi observada uma estrutura de fingers que pode ter influenciado na permeação. O ensaio de porosidade indicou que a presença de argila na membrana reduziu a quantidade de poros e o ensaio de permeação a vapor d'água ilustrou que houve uma diminuição da permeação com a adição de argila em comparação com a membrana de polisulfona pura. A membrana aditivada de argila com lítio apresentou uma redução da permeação a vapor d'água em 53\%, indicando melhores propriedades de barreira.

Palavras-chave: membrana, polisulfona, argila, propriedade de barreira.

\section{ABSTRACT}

In the present study, polysulfone membranes with addition of $3 \%$ by mass of natural montmorillonite clay, sodic and lithium, from the state of Paraiba, were developed by phase inversion method. The N-methyl-2pyrrolidone (NMP) was used as a solvent in the proportion of $80 \%$ and $20 \%$ solid. The clays and membranes were also characterized by X-ray diffraction (XRD) and Fourier transform infrared spectroscopy (FTIR). In addition, the membranes were characterized by scanning electron microscope (SEM), porosity and vapor permeation of water in order to study their behavior in gas separation applications. The XRD of the clays showed peaks of crystallinity characteristic of montmorillonite. The XRD diffractograms of membranes showed that it has possibly occurred the formation of a structure intercalated/exfoliated due to the absence of peaks related clays. By FTIR of the clays were visualized the same bands characteristic of the montmorillonite, differentiating by the cations that were changed in the structure. The FTIR of the membranes presented bands characteristic of polysulfone, and for the hybrids these bands can also be of the clays because they present the same ranges of wave number. The SEM photomicrographs showed the 
formation of a dense layer on the filter skin and on the inferior surface was observed fingers structures that may have influenced the permeation. The porosity test indicated that the presence of clay in membranes reduced the amount of pores and the permeation test using water vapor showed that there was a decrease in the permeation by adding clay in comparison to pure polysulfone membrane. The membrane with additives of clay with lithium presented a $53 \%$ reduction of gas permeation, indicating better barrier properties.

Keywords: membrane, polysulfone, clay, barrier property.

\section{INTRODUÇÃO}

A polisulfona é um polímero de engenharia caracterizado pela alta resistência térmica, oxidativa e mecânica, além de possuir excelente resistência a ácidos, bases e hidrocarbonetos [1-3]. As características deste polímero despertaram interesse para aplicação em membranas no intuito de tratar efluentes, separação de gás, nanofiltração, ultrafiltração, entre outros [4], já que esse método de separação por membranas destaca-se, em relação aos métodos tradicionais, por apresentar baixo consumo de energia, maior eficiência, processamento com etapas reduzidas e produto final de qualidade [5]. Existem diversos métodos de produção de membranas como sinterização, estiramento e gravação, porém, o método de inversão de fases se mostrou simples e eficiente gerando membranas de alta qualidade [6-9].

As membranas de polisulfona podem ser aditivadas com diversos materiais a fim de modificar suas propriedades. A adição de fibra de vidro é uma alternativa comum para aumentar as propriedades mecânicas desse polímero [1]. A adição de argilas é uma alternativa que vem sendo bastantente estudada em membranas de polisulfona a fim de otimizar a seletividade da mesma, além de alterar propriedades como mecânicas, termicas, barreira, óptica, elétrica e inflambilidade [10,11].

As argilas são contituidas por argilominerais que apresentam estrutura em camadas com espessura na escala nanométrica (alta área superficial). Esses materiais apresentam cátions que podem ser trocados para facilitarem a interação com outro material. A montmorilonita é um argilomineral que pode apresentar-se na forma policatiônica ou monocatiônica de maneira que surjam propriedades e aplicações diferentes conforme o cátion predominante. Por exemplo, as montimorilonitas sódicas tem a capacidade de inchar quando em meio aquoso, pois o sódio tem elevado número de coordenação podendo adsorver muitas moléculas de água ocasionando o inchamento, contudo, o caráter apresentado é hidrofílico. A fim de que se tenha uma interação maior com meios orgânicos é necessário fazer um tratamento de organofilização no qual um sal é introduzido entre as camadas do argilomineral ocasionando um aumento do espaçamento entre as lamelas [11]. Diversas pesquisas surgiram empregando argila montimorilonita sódica e organofilica em membranas de polisulfona a fim de aumentar a hidrofilicidade, formar um nanocompósito, melhorar as propriedades mecânicas, melhorar as propriedades de barreira, controlar as morfologias (tamanho e distribuição de poros) entre outras $[9,10,12,13,14]$.

As membranas de polisulfona apresentam excelentes propriedades de seletividade, resistência térmica, química e mecânica, porém, apresentam baixa hidrofilicidade, o que pode ocasionar incrustações superficiais prejudicando o seu desempenho [15-17]. Portanto, a fim de solucionar essa limitação foi adicionada argila montmorilonita para melhorar a seletividade e aumentar a hidrofilicidade, conforme estudos disponíveis na literatura [9,10,12,13,14]. De acordo com Medeiros et al. [18] apresentaram evidências de que o uso de argila organofílica contribuiu para redução no tamanho dos poros das membranas, diminuindo a permeação de água. Portanto, nesta pesquisa serão empregadas argilas naturais e ativadas a fim de analisar a influência dessas cargas na morfologia das membranas. As argilas provenientes da Paraíba têm sido uma alternativa viável por se tratar de um insumo naturalmente abundante e de baixo custo. Além disso, outra vantagem é que estas argilas apresentam características semelhantes às argilas importadas, logo, este trabalho tem o intuito de valorizar a matéria prima local. Estes fatores demonstram a importância do estudo da inserção destas argilas na obtenção de membranas híbridas aplicadas em separação de gás, além de servir como suporte para trabalhos futuros.

Anadão et al. [14] desenvolveram membranas de polisulfona com argila montmorilonita sódica nas concentrações de 0,5 e $3 \%$ em massa utilizando o NMP como solvente na proporção de $75 \%$ e $25 \%$ de sólido. $\mathrm{O}$ método de produção utilizado foi à inversão de fases por imersão, no qual a água destilada foi utilizada como não solvente. As membranas foram mantidas no banho de coagulação por 1 minuto e depois foram secas em um forno a vácuo a $80^{\circ} \mathrm{C}$ por 6 horas. Observou-se que a presença da argila foi responsável por aumentar a resistência térmica das membranas e melhorar as propriedades mecânicas. A ductilidade foi ligeiramente melhorada, devido o alinhamento das lamelas de argila na direção da deformação. Medidas de ângulo de contato mostraram que a hidrofilicidade da membrana foi aumentada com a adição da montmorilonita. Os padrões de DRX obtidos indicaram a formação de uma estrutura intercalada devido o 
comportamento das bandas da argila referentes ao aumento da distância basal. As membranas foram calcinadas a $300^{\circ} \mathrm{C}$ a fim de comprovar os dados obtidos por DRX. Imagens obtidas MET foram utilizadas para evidenciar a formação de uma estrutura intercalada. As imagens obtidas por MEV mostraram que houve boa dispersão da argila e boa distribuição dos poros.

Monticelli et al. [13] desenvolveram membranas de polisulfona porosas e densas com argilas montimoriloníticas sódicas (Closite $\mathrm{Na}$ ) e organofílicas (Closite 3B e Closite 93A) pelo método de inversão de fases utilizando $\mathrm{N}-$ metil - 2 pirrolidona (NMP) como solvente e água destilada como não solvente. A proporção de sólidos foi de $25 \%$ para $75 \%$ de solvente e adicionou-se 2,3 e $5 \%$ em massa de argila. As membranas obtidas foram imersas no não solvente por um tempo de 5 minutos e depois foram submetidas a um fluxo de água corrente. Foi verificado que a presença de argila altera consideravelmente as propriedades de fluxo e retenção. A Closite Na não apresentou inchamento na presença do NMP enquanto que as argilas organofílicas incharam, mas em graus diferentes. A Closite 30B foi responsável pelos maiores valores de molhabilidade (aumentou a hidrofilicidade do polímero) e módulo de elasticidade. Com o aumento da concentração de argila, a pele formada tende a diminuir de espessura e os poros tendem a aumentar conferindo à membrana um alto fluxo, porém, com baixa retenção. Para a concentração de $2 \%$, as membranas apresentaram-se menos porosas podendo ser aplicadas em ultrafiltração.

Yeh et al. [11] obtiveram membranas de polisulfona com adição de 1, 3, 5, 7 e 10\% de argila montmorilonita organofílica pelo método de dispersão da solução com a posterior retirada do solvente, conforme método de inversão de fases. O NMP (solvente utilizado) foi disperso na argila por 24 horas e depois adicionou-se o polímero e manteve a agitação por mais 12 horas. A solução foi filtrada e depois vertida em substratos de vidro para formação das membranas. O ensaio de FTIR apresentou as bandas características da argila e do polímero. O ensaio de DRX apresentou evidências de uma estrutura esfoliada, devido à ausência de bandas, e uma estrutura intercalada, devido o deslocamento das bandas da argila. As imagens de MET evidenciaram a existência de uma morfologia mista de argila intercalada e esfoliada na polisulfona. Foi observadas que pequenas quantidades de argila não alteraram as características ópticas das membranas, porém as propriedades de barreira e mecânicas foram melhoradas com a adição da argila. Foram realizados ensaios de permeação a gás que mostraram que a adição de argila dificultou a passagem do gás, ou seja, diminuição da permeabilidade.

Sur et al. [10] prepararam membranas de polisulfona com concentrações de 1, 3 e 5\% em massa de argila montmorilonita organofílica. As membranas foram preparadas pelo método de inversão de fases, onde a solução foi agitada, utilizando o dimetilacetamida como solvente, a $80^{\circ} \mathrm{C}$ por 24 horas. As análises de DRX mostraram ausência das bandas da argila indicando a formação de um nanocompósito esfoliado ou um microcompósito. As imagens fornecidas por MET apresentaram evidências da formação de nanocompósitos esfoliados. Os maiores valores de resistência à tração foram obtidos para concentração de $3 \%$ de argila indicando um aumento das propriedades mecânicas com a adição de argila, porém, para a concentração de $5 \%$ houve uma diminuição dessas propriedades. O alongamento apresentou uma queda para as concentrações de 1 e $3 \%$, mas aumentou para a concentração de $5 \%$. Os resultados da análise térmica mostraram que houve um aumento da estabilidade térmica com a adição de argila dificultou a passagem do gás, ou seja, diminuição da permeabilidade.

Diante do exposto, esse trabalho tem como objetivo a avaliação da influência na modificação da argila na morfologia e permeação das membranas híbridas assimétricas para aplicação na separação de gás.

\section{MATERIAIS E MÉTODOS}

\subsection{Materiais}

Foi utilizada argila montmorilonita verde lodo retirada da mina Bravo do município de Boa Vista/Paraíba. As argilas são naturalmente policatiônicas, mas realizou-se um tratamento de ativação (troca dos cátions) no Laboratório de Tecnologia dos Materiais (LTM) da Unidade acadêmica de Engenharia de Materiais da Universidade Federal de Campina Grande utilizando-se carbonato de sódio e de lítio na concentração $2 \mathrm{~N}$ para obter as argilas sódicas e com lítio, respectivamente. As argilas foram preparadas no teor de 100 meq/100 g de argila seca no qual se esperou um período de 5 dias para que os cátions fossem trocados. Posteriormente, as amostras foram lavadas com água destilada, secas e trituradas. O polímero utilizado foi a polisulfona UDEL P3500 LCD MB7 com massa molar entre $77.000 \mathrm{~g} / \mathrm{mol}$ e $83.000 \mathrm{~g} / \mathrm{mol}$ e densidade relativa de 1.2, segundo ASTMD 792. Foi utilizado o 1-Metil 2-Pirrolidona (NMP) como solvente com pureza de $99.5 \%$ comprado da empresa Synth. 


\subsection{Preparação das amostras}

O polímero foi colocado para secar em uma estufa a $80{ }^{\circ} \mathrm{C}$ por 24 horas. A argila também foi seca em uma estufa por 24 horas, porém, a $70{ }^{\circ} \mathrm{C}$. Depois de retirados da estufa, o polímero e a argila foram colocados em uma estufa a vácuo na temperatura ambiente para evitar que absorvam umidade. Foram preparados quatro tipos de membranas: polisulfona pura, polisulfona e argila natural (policationica), polisulfona e argila ativada com sódio (monocatiônica) e polisulfona e argila ativada com lítio (monocatiônica). As concentrações para as quatro membranas foram de $80 \%$ do solvente (NMP) para $20 \%$ de sólido. A porção de sólido contem $3 \%$ de argila para as membranas híbridas. Para a membrana pura foi pesado $160 \mathrm{~g}$ do solvente (NMP) e $40 \mathrm{~g}$ do polímero. Para as membranas híbridas foram pesados $160 \mathrm{~g}$ do solvente, $38.8 \mathrm{~g}$ do polímero e $1.2 \mathrm{~g}$ da argila.

\subsection{Preparação das membranas poliméricas e híbridas}

No preparo das membranas híbridas adicionou-se 160 gramas do solvente junto com 1.2 gramas de argila em um becker e colocou-se para agitar no agitador Fisatom 713 D em uma velocidade de 500 rotações por minuto por uma hora. Depois foram adicionados 38.8 gramas do polímero e mantidos sob a mesma agitação por 4 horas. Em seguida, a solução foi vertida em uma placa de vidro através do espalhamento da solução sob o substrato com uso de um bastão de vidro de modo que se formasse uma camada homogênea, onde se esperou um minuto após o espalhamento da membrana e então os imergiu (placa + membrana) em um recipiente com 2 litros de água destilada. Após esse procedimento, a membrana foi retirada. No caso da membrana pura, procedeu-se da mesma forma, sem a presença da argila, ou seja, adicionou-se o solvente juntamente com o polímero e a agitação foi mantida a 500 rotações por minuto por quatro horas. Esses procedimentos foram realizados à temperatura ambiente (em torno de $24^{\circ} \mathrm{C}$ ).

\subsection{Caracterizações das membranas poliméricas e híbridas}

\subsubsection{Difração de raios-X (DRX)}

As membranas foram analisadas no equipamento shimadzu xdr-6000 à temperatura ambiente, utilizando radiação cu $\mathrm{k} \alpha\left(\lambda=1,5418\right.$ å), tensão de $40 \mathrm{kv}$, corrente de $30 \mathrm{ma}$, varredura de $2^{\circ}$ a $30^{\circ}$ e velocidade de varredura de $2 \% \mathrm{~min}$. As argilas foram analisadas pelo mesmo equipamento, porém, apresentaram-se passadas em peneira abnt $\mathrm{n}^{\circ} 200(0,074 \mathrm{~mm})$, passo de $0,02^{\circ}$ e varredura de 0 a $60^{\circ}$.

\subsubsection{Espectroscopia na região do infravermelho com transformada de Fourier (FTIR)}

As análises por FTIR foram realizadas no espectrômetro PERKIN-ELMER SPECTRUM 400, com varredura de 4000 a $650 \mathrm{~cm}^{-1}$. As amostras de argila foram caracterizadas na forma de pó, enquanto as membranas na forma de filmes finos.

\subsubsection{Microscopia eletrônica de varredura (MEV)}

As fotomicrografias da morfologia das membranas foram realizadas por microscopia eletrônica de varredura utilizando o equipamento de marca TESCAN, modelo VEGA3 e tensão de $20 \mathrm{kV}$. Foram analisadas a superfície de topo e a secção transversal das membranas. Na análise da seção transversal, as amostras foram fraturadas em nitrogênio líquido para evitar deformação plástica, ou seja, evitar que a membrana se deforme e prejudique a morfologia estabelecida. As superfícies das membranas foram revestidas com ouro ("sputtering" - Metalizador Shimadzu-IC-50, utilizando uma corrente de $4 \mathrm{~mA}$ por um período de 3 minutos).

\subsubsection{Determinação da porosidade das membranas}

\subsubsection{Método 1}

Anadão et al. [19] desenvolveram membranas de polisulfona adicionada com grafite na concentração de 3\% em massa. Foi utilizada uma fração de $25 \%$ de sólido e $75 \%$ de 1-Metil 2-Pirrolidona (solvente) no método de inversão de fases. A porosidade da membrana pura foi determinada pela Equação 1:

$$
\text { poro }=\frac{l \cdot A-(m-p) p o l}{l \cdot A}=\frac{\text { vporo }}{\text { vtotal }}=\frac{\text { vtotal }- \text { vpol }}{\text { vtotal }}
$$


Em que $l$ é a espessura da membrana; $A$ é a área da membrana; $m$ é a massa da membrana; $p$ é a densidade do polímero; vtotal é o volume da membrana; vporo é o volume do poro e vpol é o volume do polímero.

Para as membranas híbridas utilizou-se a seguinte Equação 2:

$$
\text { poro }=\frac{l . A-[t p o l .(m / p) p o l+t c e r .(m / p) c e r}{l . A}
$$

Onde tpol é a proporção em massa do polímero e tcer é a proporção em massa das argilas.

\subsubsection{Método 2}

Bellincantaet al. [20] desenvolveram membranas de polisulfona/poliuretano pelo método de inversão de fases. Adicionou-se fotoiniciadores nas membranas de modo que as mesmas foram irradiadas com lâmpadas ultravioletas a fim de aumentar a interação entre os polímeros e o suporte utilizado. Entre as várias caracterizações realizadas foram feitas as determinações das densidades e das porosidades das membranas. A densidade foi determinada segundo norma ASTM D 792-08, em que as membranas foram imersas em água destilada por 48 horas e o peso das mesmas foi medido. A porosidade também foi determinada com a imersão das membranas em água por 48 horas e as massas das mesmas foram medidas, aplicando-se à Equação 3.

$$
p=\frac{\frac{M b}{P b}}{\frac{M b}{P b}+\frac{M p}{d}} \times 100
$$

Em que $p$ é a porosidade da membrana, $M b$ é a massa absorvida de água, $\mathrm{Pb}$ é a densidade da água, $M p$ é a massa inicial da membrana e $d$ é a densidade da membrana.

\subsubsection{Método 3}

Weiet al. [21] e Yang et al. [22] desenvolveram membranas de polisulfona no qual modificaram as mesmas com aplicação de ácido cítrico e sódio bisulfito, que são produtos químicos normalmente utilizados em membranas no pré-tratamento de água, a fim de otimizar o rendimento das mesmas nos processos de separação. Dentre as caracterizações empregadas, determinou-se a porosidade das membranas com a imersão delas em água destilada por 48 horas em que se determinaram as respectivas massas, com uso de uma balança analítica, e os dados foram aplicados na Equação 4.

$$
P=\frac{(M m-M s) / \rho}{A \cdot L}
$$

Em que $P$ é a porosidade, $M m$ é a massa da membrana depois de imersa na água destilada por 48 horas, $M s$ é a massa da membrana antes da imersão, $\rho$ é a densidade da água, $A$ é a área da membrana e $L$ é a espessura da membrana.

Para todos os métodos utilizou-se os seguintes dados: a densidade do polímero utilizada foi $1,24 \mathrm{~g} / \mathrm{cm}^{3}$ segundo valor fornecido na ficha técnica do mesmo, a densidade da argila utilizada foi $2,5563 \mathrm{~g} / \mathrm{cm}^{3}$ determinada pelo Ultrapyc 1200e (automatic density analyzer) da empresa Quantachrome Instruments. A espessura das membranas foi determinada pelo método dos pontos múltiplos utilizando um micrômetro digital, no qual se obteve a espessura de quatro regiões diferentes da membrana, obtendo-se a média dos valores. No método 1, houve a pesagens das membranas com uso de uma balança analítica e determinação da espessura e área utilizada e aplicando as Equações 1 e 2. Nos métodos 2 e 3 as membranas foram pesadas e depois imersas em água destilada por 48 horas e posteriormente pesadas, depois aplicou-se os dados nas Equações 3 e 4 . Os ensaios foram realizados em triplicata com a temperatura em torno de $24{ }^{\circ} \mathrm{C}$.

\subsubsection{Permeação a vapor d'água}

Este ensaio foi realizado segundo a norma ASTM E96 [23], utilizando-se o método gravimétrico, no Laboratório de Membranas/CCT/UFCG. Foi determinado o peso e a espessura das membranas, 
posteriormente, as mesmas foram cortadas e coladas (com adesivo comercial à base de resina epóxi) em recipientes de vidros (cilíndricos) contendo um determinado volume de água de modo que o sistema estivesse hermeticamente fechado. Os recipientes foram colocados em uma caixa plástica contendo sílica (utilizada para controlar a umidade do ar) e vedados de maneira que não houvesse contato com o meio externo. A umidade relativa do ar e a temperatura foram acompanhadas mantendo-se em torno de $27 \%$ e $24{ }^{\circ} \mathrm{C}$, respectivamente. Os recipientes foram pesados em tempos determinados durante uma semana. $\mathrm{O}$ experimento foi realizado em triplicata. A permeabilidade dos filmes foi determinada segundo a Equação 5.

$$
P=\frac{G \cdot h \cdot V 0}{M \cdot P v \cdot \Delta u}
$$

Em que $P$ é a permeabilidade dos filmes em barrer, $G$ é a massa que passa através do filme por unidade de área e tempo que foi determinada pelo cálculo da inclinação da reta da perda de massa dos potes por unidade de área em função do tempo, $h$ é a espessura do filme, $V 0$ é $22,414 \mathrm{~cm}^{3} \cdot \mathrm{mol}^{-1}$ que é o volume molar normal em condições padronizadas de temperatura e de pressão $\left(0{ }^{\circ} \mathrm{C}, 1 \mathrm{~atm}\right)$ do vapor de água, $M$ é $18,011 \mathrm{~g} \cdot \mathrm{mol}^{-1}$ que é a massa molar da água, $P v$ é a pressão de vapor da água à temperatura do experimento e $\Delta u$ é a diferença de umidade relativa do ar entre o interior do pote e o exterior.

\section{RESULTADOS E DISCUSSÃO}

\subsection{Difração de raios-X (DRX)}

A Figura 1 ilustra os difratogramas de DRX das argilas evidenciando os picos de cristalinidade característicos das mesmas. Embora as argilas apresentem cátions diferentes, a sua cristalinidade não é alterada, pois os cátions por serem pequenos não causam distorções nas lamelas da argila, logo, não alteram a cristalinidade, ou seja, os picos são mantidos. Podem-se observar picos característicos de argilas montmorilonitas, tais como: montmorilonita (M), caulinita (C) e quartzo (Q).

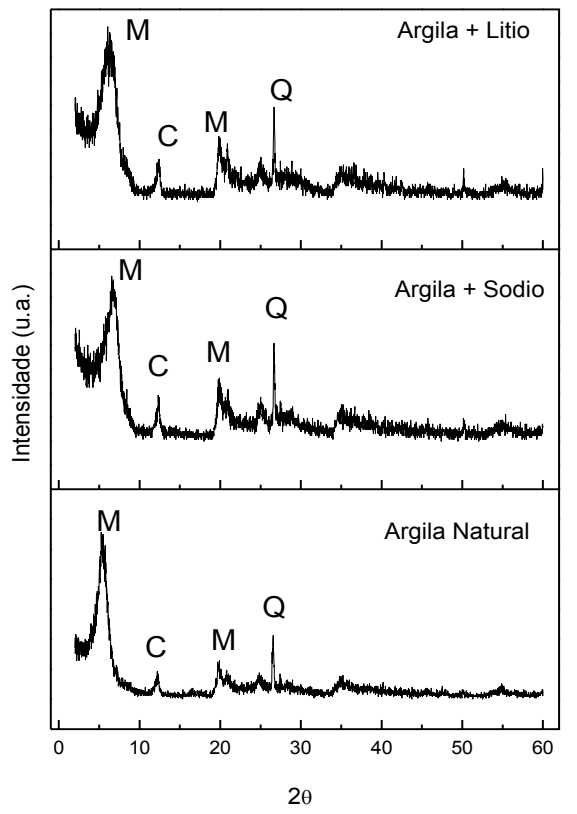

Figura 1: Difratogramas de DRX da argila montmorilonita pura, ativada com sódio e ativada com lítio.

A Figura 2 apresenta os difratogramas de DRX das membranas de polisulfona pura e com argila natural, sódica e com lítio. O DRX da polisulfona pura apresentou um pico característico entre $15^{\circ}$ e $20^{\circ}$ referente à sua estrutura, conforme foi observado também por Anadão et al. [11]. As membranas híbridas apresentaram basicamente o mesmo comportamento com um pico característico da estrutura da polisulfona e a ausência das bandas característicos da argila, conforme verificado na Figura 6. Pode-se notar que a 
membrana aditivada de argila com lítio apresentou uma maior linearidade na região em que se esperariam os picos da argila, dando indícios que houve uma maior intercalação/esfoliação das lamelas do argilomineral.

Os difratogramas das membranas híbridas podem evidenciar, de modo geral, que houve a formação de um nanocompósito intercalado/esfoliado ou de um microcompósito já que os picos característicos das argilas, situadas entre 0 e $20^{\circ}$, apresentadas na Figura 1, não foram evidenciadas na Figura 2. Portanto, indicando que a estrutura cristalina da argila foi alterada (pela presença das cadeias poliméricas entre as lamelas) ou que houve um aglomerado das mesmas que pode ter impedido a identificação das bandas.

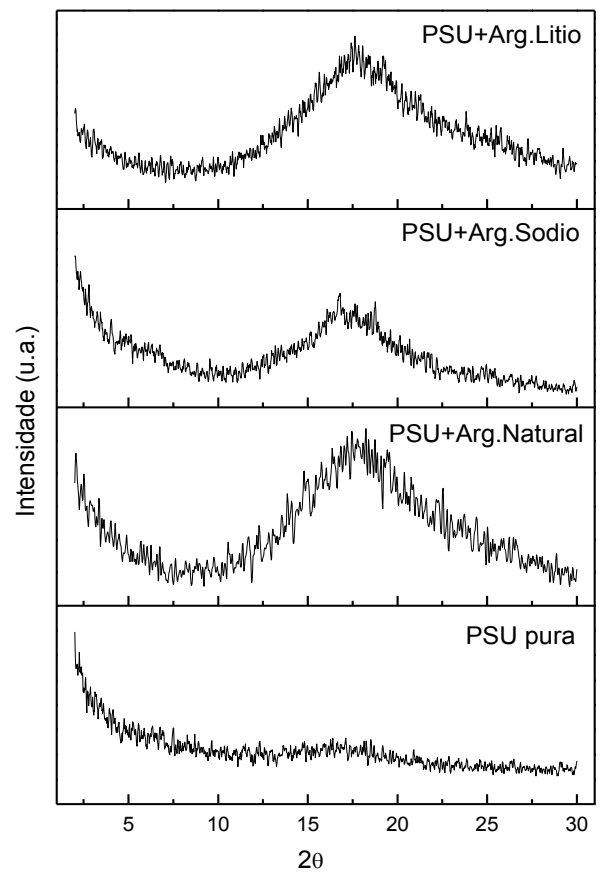

Figura 2: Difratogramas de raios-X das membranas híbridas e polimérica com presença do pico característico da polisulfona.

\subsection{Espectroscopia na região do infravermelho com transformada de Fourier (FTIR)}

A Figura 3 apresenta as análises por FTIR das argilas. Na Figura 3, as argilas apresentam as mesmas bandas características por se tratarem de montmorilonitas que é o seu principal argilomineral. A diferença entre elas consiste apenas nos cátions que foram trocados na estrutura, uma policatiônica, outra com predominância do cátion sódio e a outra do cátion lítio, porém, não houve evidências de bandas específicas para identificação desses cátions. As principais bandas apresentadas são: banda característica de ligações $\mathrm{Si}-\mathrm{O}-\mathrm{Si} \mathrm{em} 988 \mathrm{~cm}^{-1}$; em $795 \mathrm{~cm}^{-1}$, banda característica da camada octaédrica; em $908 \mathrm{~cm}^{-1}$, banda referente à frequência de vibração angular da hidroxila ligada ao alumínio no sítio octaédrico; em $1640 \mathrm{~cm}^{-1}$, banda referente à água adsorvida; em $3622 \mathrm{~cm}^{-1}$, banda característica do estiramento da hidroxila e, em $3690 \mathrm{~cm}^{-1}$, sugere-se a presença de caulinita. Esses picos também foram observados por Sharma e Purkait [24], Menezes et al. [25], Nóbrega et al [26] e Pereira [27]. 


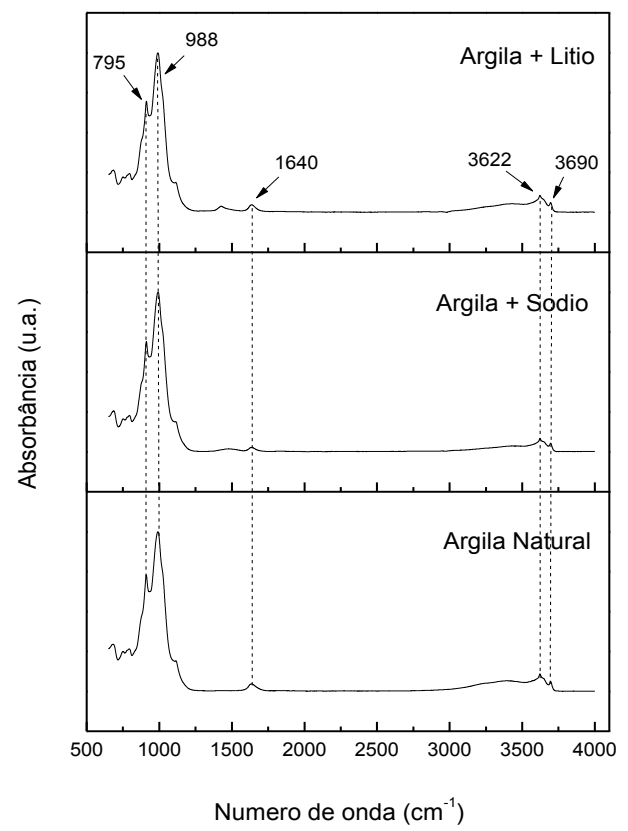

Figura 3: Espectros de FTIR das argilas natural, ativada com sódio e com lítio.

Na Figura 4 estão apresentadas as análises por FTIR das membranas de polisulfona pura e com argila natural, sódica e com lítio.

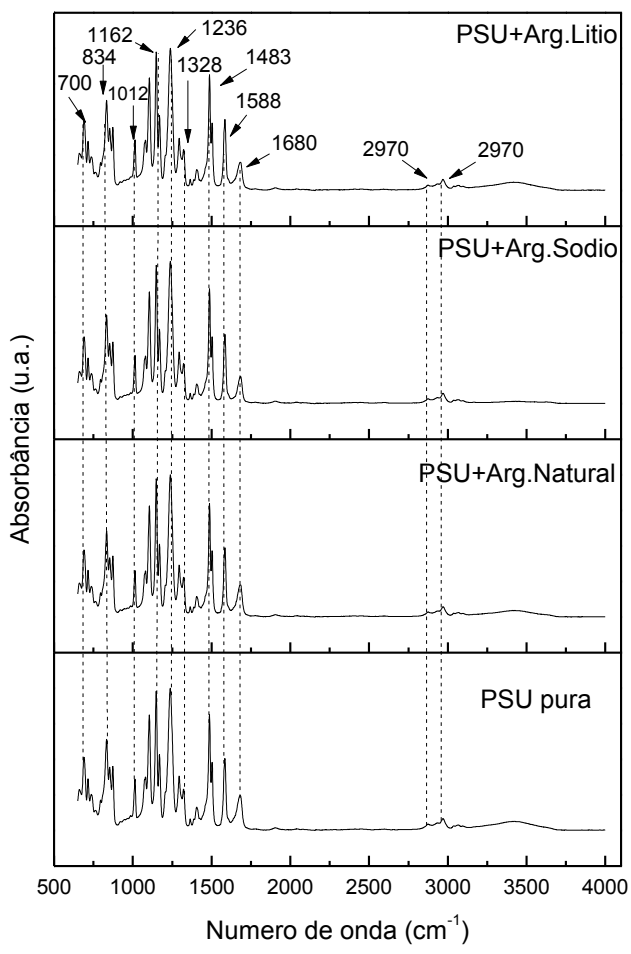

Figura 4: Espectros de FTIR das membranas pura, com argila sódica e argila com lítio.

A partir da Figura 4, podem-se constatar as bandas características do polímero que são: em $1162 \mathrm{~cm}^{-1}$, referente ao estiramento simétrico da sulfona; em $1236 \mathrm{~cm}^{-1}$, do éter aromático; em $1328 \mathrm{~cm}^{-1}$, do estiramento assimétrico da sulfona; em $2970 \mathrm{~cm}^{-1}$, do estiramento aromático do $\mathrm{CH}_{3}$; em $2876 \mathrm{~cm}^{-1}$, referente ao estiramento alifático do $\mathrm{CH}_{3}$, em 1483 e $1588 \mathrm{~cm}^{-1}$, referentes ao estiramento C-C dos aromáticos; em 1012 $\mathrm{cm}^{-1}$, referente ao estiramento C-O assimétrico e em $700 \mathrm{~cm}^{-1} \mathrm{e}, \mathrm{em} 834 \mathrm{~cm}^{-1}$, referente à vibração molecular tipo rockingda ligação $\mathrm{C}-\mathrm{H}$. Esses picos característicos também foram evidenciados nos trabalhos de Yeh et 
al. [11], Wei [21], Santos [28], Mushtaq [29]. Além disso, foi observado as mesmas bandas referentes à polisulfona e de seus híbridos. Entretanto, estas bandas não estão relacionadas somente com a polisulfona, mas também são inerentes às bandas características típicas das argilas (natural, com sódio e com lítio), conforme apresentado anteriormente. Elas permaneceram superpostas às bandas da polisulfona por apresentarem as mesmas faixas de número de onda.

\subsection{Microscopia eletrônica de varredura (MEV)}

As fotomicrografias obtidas por MEV da superfície de topo e da seção transversal das membranas de polisulfona pura e com argila natural, sódica e com lítio estão apresentadas nas Figuras de 5 a 8 . As membranas apresentaram uma morfologia anisotrópica integral que pode ser atribuída ao método de preparo por inversão de fases e pela atuação da argila, no caso das membranas híbridas.
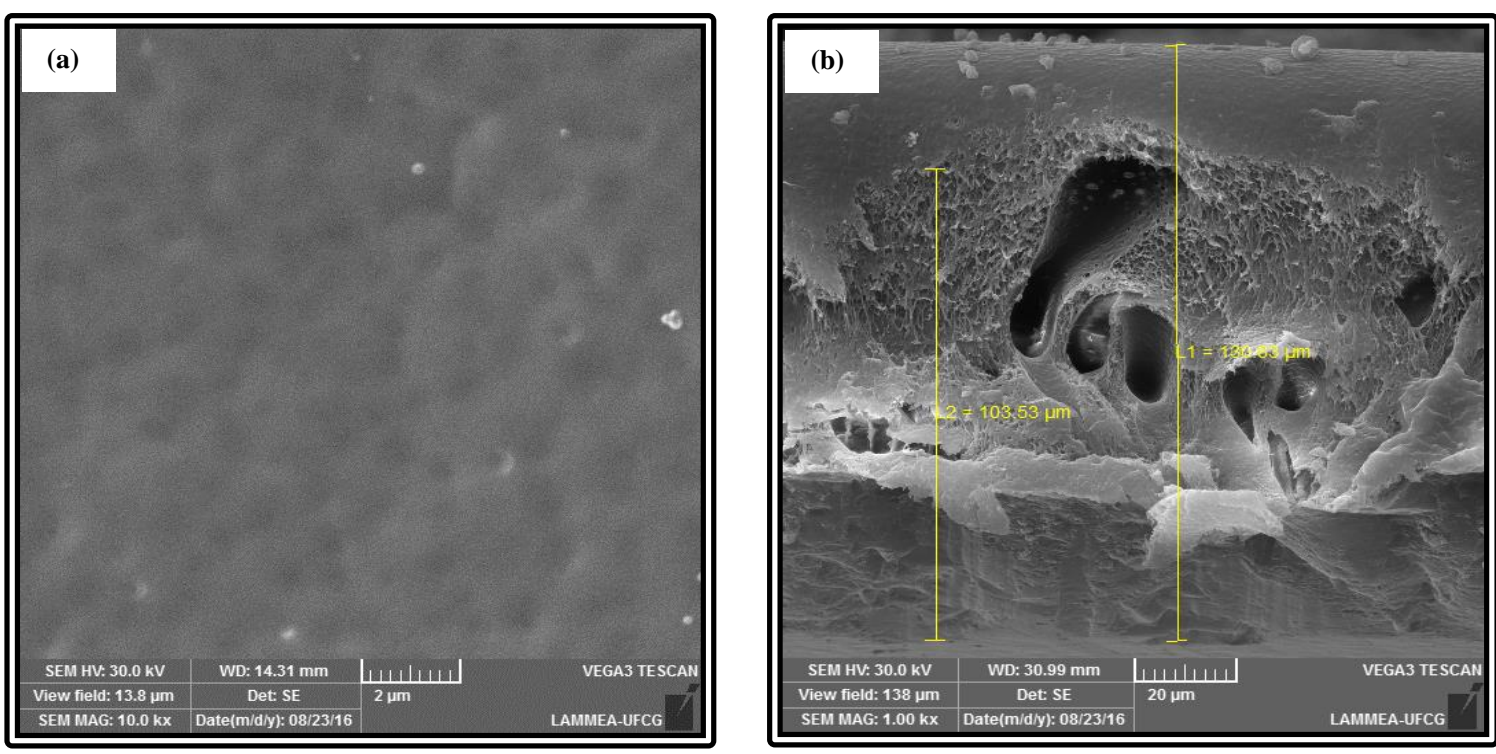

Figura 5: Fotomicrografias de MEV da PSU pura: (a) superfície de topo e (b) seção transversal.
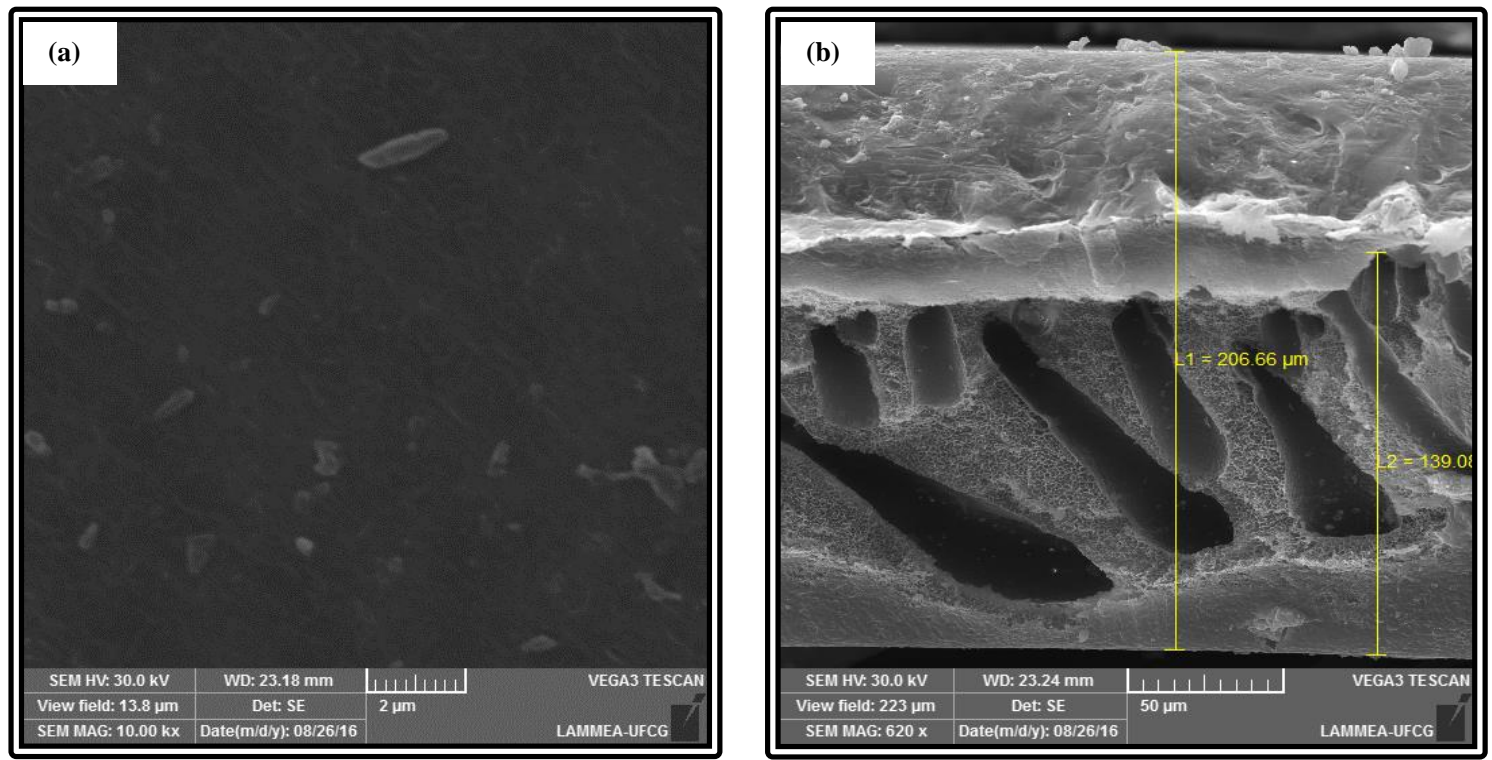

Figura 6: Fotomicrografias de MEV da PSU+arg. natural: (a) superfície de topo e (b) seção transversal. 

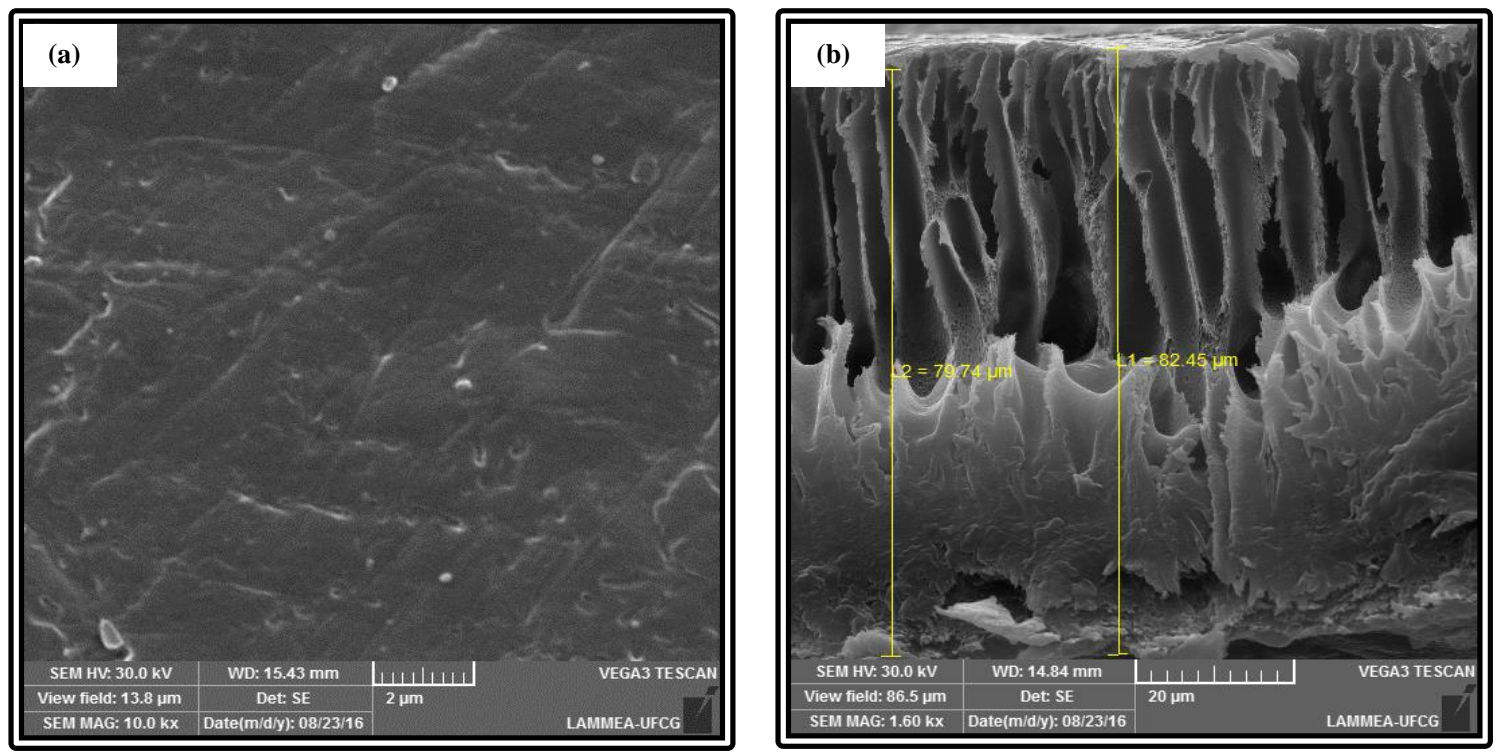

Figura 7: Fotomicrografias de MEV da PSU+arg. sódio: (a) superfície de topo e (b) seção transversal.
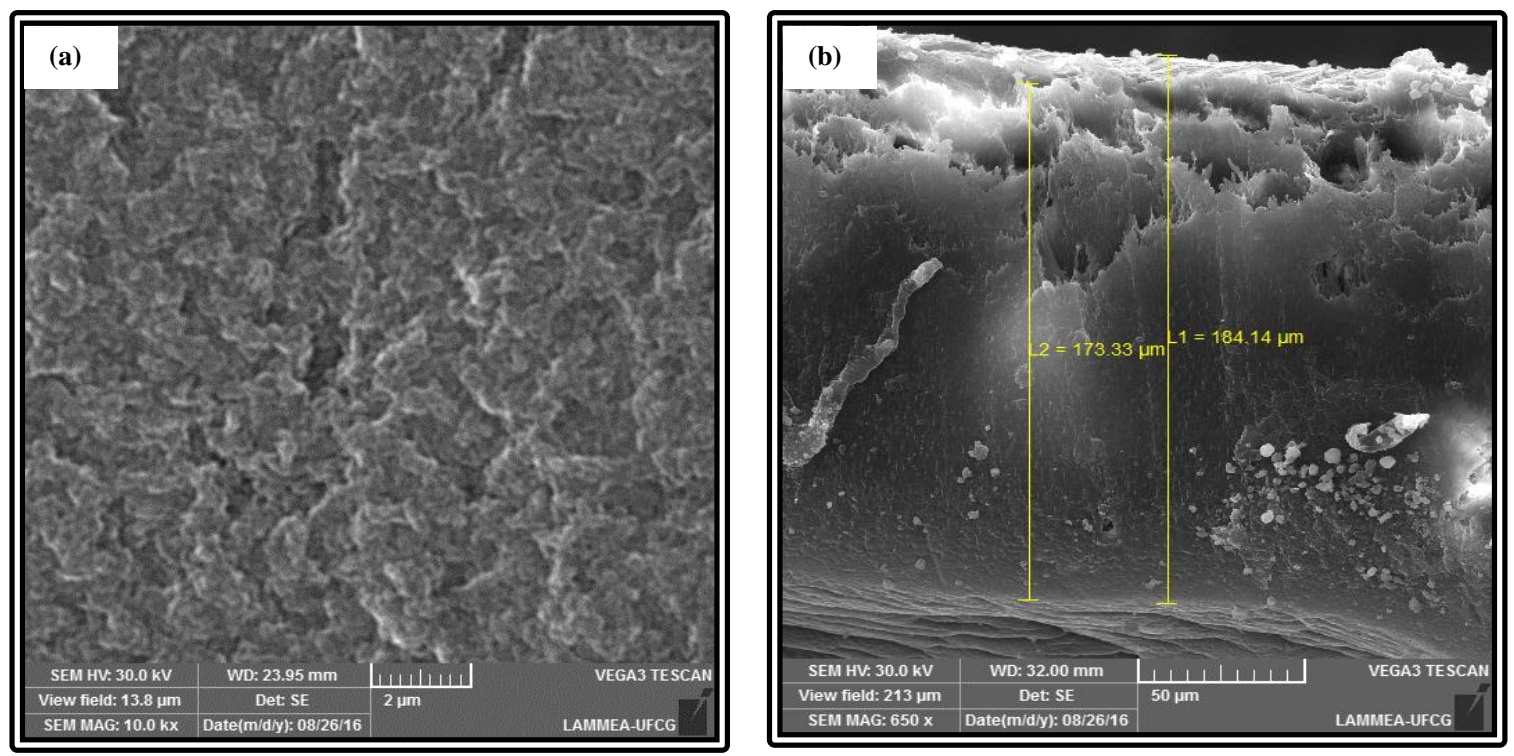

Figura 8: Fotomicrografias de MEV da PSU+arg. lítio: (a) superfície de topo e (b) seção transversal.

Na técnica de inversão de fases ocorre um fluxo mássico difusivo, devido à diferença de potencial químico entre o solvente (NMP) e o não solvente (água destilada) que se inicia na região da superfície de topo da membrana, região oposta a que está em contato com o substrato de vidro, e mantido por toda seção, porém, com intensidades diferentes. O fluxo na superfície é influenciado pelo tempo de exposição (1 minuto) antes da precipitação da solução polimérica, já que esse tempo pode ter permitido que o solvente localizado no topo evapore, de modo que ocorra uma maior concentração de polímero. Esse fato pode ter contribuído para a formação de uma camada densa inicial, com ausência de poros para o aumento utilizado, dando indícios que houve uma precipitação direta do polímero sem formação de fase líquido-líquido (que podem ocasionar uma estrutura porosa). Logo abaixo desta camada, ao longo da seção transversal, formou-se uma camada com uma estrutura de fingers com poros alongados, provavelmente devido à diminuição da intensidade do fluxo mássico entre o NMP e a água ocasionado pela formação da camada densa [19].

Vale ressaltar que no método por inversão de fases pode haver um alinhamento das lamelas de argila e das cadeias poliméricas, devido o modo de espalhamento da solução no substrato, na região superficial da membrana. Isto pode ocasionar em uma barreira física desses componentes que podem ter influenciado na morfologia. 
Observou-se a formação de pequenos aglomerados na superfície das membranas vistas nas Figuras 5(a), 6(a) e 7(a) e na seção transversal das Figuras 5(b), 6(b) e 8(b) que podem ser atribuídos à presença de polímero não solubilizado. O tamanho e a quantidade destes não dão indícios de que sejam aglomerados de argila, pois as mesmas foram adicionadas em pequenas quantidades nas membranas híbridas.

A Figura 5(b) apresenta a estrutura morfológica da membrana pura, na qual se pode observar uma camada densa inicial seguida de uma estrutura com fingers. A membrana com adição de argila natural, Figura 6(b) apresentou uma estrutura com uma camada densa maior que a membrana pura, porém com fingers em maiores quantidades e mais bem distribuídos. A Figura 7(b), membrana com argila sódica, apresentou uma camada densa maior que a membrana pura e uma estrutura de fingers semelhante à membrana com argila natural. Essas morfologias podem ser atribuídas à presença da argila que pode ter atuado como barreiras físicas que dificultaram o fluxo difusivo entre o solvente e o não solvente, de modo que a camada densa, inicialmente formada, fosse reduzida contribuindo no aumento da camada visualizada abaixo do topo e ao longo da seção transversal. A membrana com argila natural apresentou uma camada densa maior que as demais híbridas devido, provavelmente, a pouca interação entre o polímero e a argila de modo que não ocorreu uma intercalação/esfoliação das lamelas do argilomineral.

Na Figura 8, a membrana de argila com lítio, apresentou uma morfologia diferente das outras três, com uma superfície de topo com rugosidade e a ausência de fingers na sua seção transversal, isto é, uma estrutura simétrica e densa, segundo os aumentos utilizados. Essa morfologia pode ser atribuída a uma maior expansão das lamelas da argila, causada pela presença do cátion lítio, promovendo uma maior interação com o polímero. Desta forma, o fluxo mássico dos líquidos (solvente e não solvente) foi, possivelmente, facilitado pelas características difusiva do processo e pela afinidade do fluxo com a membrana, de modo que o transporte mássico fosse mais homogêneo ao longo da seção, ocasionando uma camada densa mais extensa se comparado com as demais membranas.

\subsection{Porosidade}

Os resultados dos três métodos utilizados para determinação da porosidade das membranas de polisulfona pura e com argila natural, sódica e com lítio estão apresentados na Tabela 1.

Pode-se observar que houve uma variação na porosidade, propiciando uma diminuição discreta na porosidade das membranas com argila, se comparadas com a membrana pura. De maneira geral, a membrana de PSU pura apresentou maior porosidade, absorvendo uma maior quantidade de água, provavelmente por possuir uma camada densa menos espessa, vista por MEV pela sua interface com a camada inferior e, além disso, trata-se de um polímero com caráter hidrofílico [30]. A adição das argilas acarretou no aumento da espessura de suas camadas densas, impedindo uma identificação da interface da camada superior e inferior destas membranas, ficando mais evidente para a membrana com a adição da argila com lítio. Este fato ocorreu, possivelmente devido as argilas terem atuado como agente nucleante [31], aumentando o caminho tortuoso existente na sua parte interna, diminuindo desta forma, as suas porosidades e, consequentemente, a absorção de água destas membranas híbridas.

Tabela 1: Valor da porosidade da membrana pura e das membranas híbridas com os 3 métodos sugeridos.

\begin{tabular}{c|c|c|c}
\hline Membranas & Porosidade 1 $(\boldsymbol{\%})$ & Porosidade 2 $\mathbf{( \% )}$ & Porosidade 3 $\mathbf{( \% )}$ \\
\hline PSU pura & $74,2 \pm 2,04$ & $59,74 \pm 1,56$ & $38,09 \pm 4,37$ \\
\hline PSU+Arg. Natural & $72,78 \pm 0,82$ & $53,42 \pm 1,6$ & $32,93 \pm 2,05$ \\
\hline PSU+Arg. Sódio & $74,8 \pm 0,14$ & $54,89 \pm 2,63$ & $32,12 \pm 3,9$ \\
\hline PSU+Arg. Lítio & $74 \pm 0,72$ & $57,39 \pm 1.42$ & $36,47 \pm 2,73$ \\
\hline
\end{tabular}

\subsection{Permeação a vapor d'água}

A Figura 9 ilustra a permeação a vapor d'água das membranas de polisulfona pura e com argila natural, sódica e com lítio.

A membrana pura de polisulfona apresentou o maior valor de permeação, enquanto que, as membranas com as argilas natural, sódica e com lítio apresentaram gradativamente os menores valores de permeação a vapor d’água, podendo ser justificados pelas morfologias obtidas [32].

As membranas com as argilas sódicas e com lítio apresentaram por DRX uma estrutura possivelmente intercalada/esfoliada indicando uma boa interação entre o polímero e as lamelas da argila, agindo como barreiras físicas para passagem do vapor d'água [33]. Logo, esses caminhos tortuosos ocasionados pelas suas lamelas impediram a passagem do vapor, representando uma diminuição da sua permeação pelas membranas. 


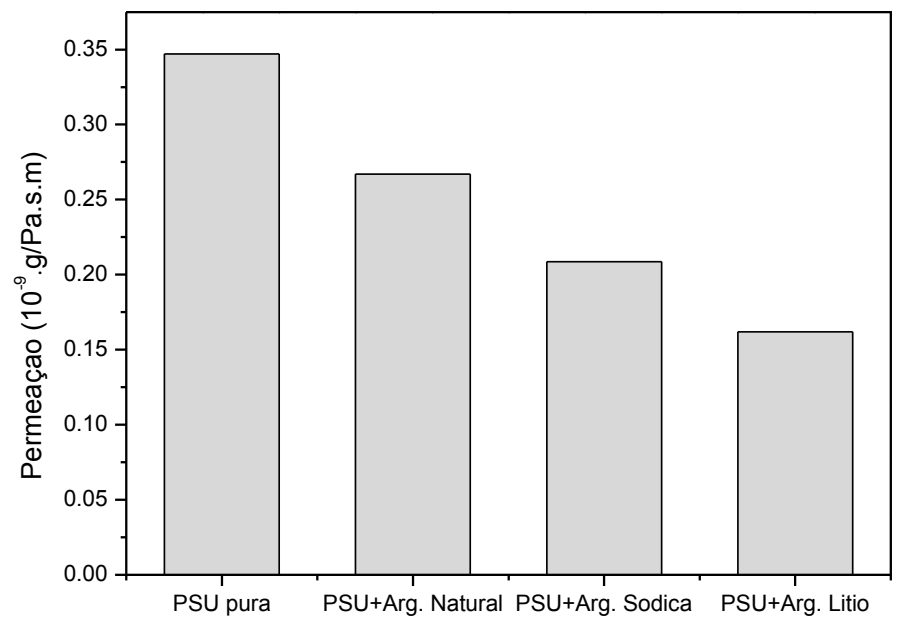

Figura 9: Valores da permeação a vapor d'água para a membrana pura e as membranas híbridas.

A membrana com a argila lítica apresentou menor permeação, provavelmente devido a melhor distribuição das lamelas da argila que agiram como agente nucleante, devido a maior facilidade do lítio ser trocado pelos cátions, apresentando uma boa interação do íon no argilomineral, melhorando a sua compatibilidade com o polímero. Os cátions de lítio em água, devido seu menor raio iônico dentre os metais alcalinos e, consequentemente, por apresentarem um elevado potencial de campo elétrico sobre a carga, são os que mais são solvatados por água (apresentam na camada de solvatação primária em torno de 11 moléculas de água comparativamente a apenas 5 dos íons sódio). Portanto, este pode ser um indicativo da forte redução observada nos ensaios de permeação a vapor de água.

A literatura tem reportado resultados significativos de membranas de polisulfona com argila montmorilonita para permeação de gases, dificultando a passagem de oxigênio e nitrogênio [10, 11, 13, 14]. Esta pesquisa, utilizando membrana de polisulfona com argila lítica, apresentou boas propriedades de barreira, diminuindo a permeação a vapor de água pela membrana. Além disso, a seção transversal visualizada por MEV da membrana de polisulfona com argila lítica apresentou uma estrutura mais densa com ausência de fingers, que também pode ter sido responsável pelo seu baixo valor de permeação ao vapor d'água. Portanto, nota-se que o uso da membrana de polisulfona com argila lítica reduziu a permeação a vapor d'água em 53\% em comparação à membrana pura.

\section{CONCLUSÕES}

Membranas de polisulfona com argila natural, sódica e lítica foram obtidas com sucesso. Diante dos resultados apresentados, concluiu-se que a adição da argila na obtenção das membranas assimétricas, independente do cátion trocado, promoveu mudanças na sua microestrutura, variando o tamanho de aglomerados e a quantidade de poros obtidos na superfície de topo, bem como a formação de fingers nas suas seções transversais. Estas argilas atuaram como agente nucleante, propiciando uma morfologia com porosidade adequada e, desta forma, reduzindo a permeação a vapor d'água se comparado com a membrana de polisulfona pura. Além disso, a membrana de polisulfona com argila lítica reduziu a permeação a vapor d'água em $53 \%$, indicando boa propriedade de barreira.

\section{AGRADECIMENTOS}

Os autores agradecem à Bentonit União Nordeste (BUN) pelo fornecimento da argila, à CAPES/PNPD, ao MCTI/CNPq, à PETROBRAS e ao PRH-25/ANP pelo auxílio financeiro.

\section{BIBLIOGRAFIA}

[1] WIEBECK, H., HARADA, J. "Plásticos de engenharia". Artliber Editora, São Paulo, 2005.

[2] SHARMA, N., PURKAIT, M. K. "Impact of synthesized amino alcohol plasticizer on the morphology and hydrophilicity of polysulfone ultrafiltration". Journal of Membrane Science, v. 522, pp. 202-215, Jan. 2017. 
[3] YUAN, H. G., LIU, Y. Y., LIU, T. Y., et al., "Self-standing nanofilms of polysulfone doped with sulfonated polysulfone via solvent evaporation for forwards osmosis". Journal of Membrane Science, v. 523, pp. 567-575, Fev. 2017.

[4] HABERT, A. C., BORGES, C. P., NÓBREGA, R. "Processo de separação com membranas", $1^{\text {a }}$ ed., EPapers Serviços Editoriais Ltda, Rio de Janeiro, 2006.

[5] SOUZA, J. F., FERRARINI, E., RIVEROS, R., et al., "preparação e caracterização de membranas enantioseletivas de polisulfona com lipase imobilizada", Revista Iberoamericana de Polímeros, v. 9, n.1, pp. 54-61, Jan. 2008.

[6] WANG, X. L., QIAN, H. J., CHEN, L. J., et al., "Dissipative particle dynamics siulation on the polymer membrane formation by immersion precipitation", Journal of Membrane Science. v. 311, n. 1-2, pp. 251-258, Mar. 2008.

[7] CHAKRABARTY, B., GHOSHAL, A. K., PURKAIT, M. K. "Preparation, characterization and performance studies of polysulfone membranes using PVP as an additive", Journal of Membrane Science. v. 315, n. 1-2, p. 36-47, Mai. 2008.

[8] HAN, S., MAO, L, WU, T., et al., "Homogeneous polyethersulfone hybrid membranes prepared with insuit synthesized magnesium hydroxide nanoparticles by phase inversion method". Journal of Membrane Science. v. 516, p. 47-55, Out. 2016

[9] CHEN, S. H., LIOU, R. M., LIN, Y. Y., et al., "Preparation and Characterization of Asymmetric Sulfonated Polysulfone Membranes by Wet Phase Inversion Method”. European Polymer Journal. v. 45, n. 4, p. 1293-1301, Abr. 2009.

[10] SUR, G. S., SUN, H. L., LYU, S. G., et al., "Synthesis, structure, mechanical properties, and thermal stability of some polysulfone/organoclay nanocomposite”, Polymer. v. 42, n. 24, pp. 9783-9789, Nov. 2001.

[11] YEH, J. M., CHEN, C. L., CHEN, Y. C., et al., "Enhanced corrosion prevention effect of polysulfoneclay nanocomposite materials prepared by solution dispersion”. Journal of Applied Polymer Science. v. 92, n.1, pp. 631-637, Abr. 2004.

[12] SANTOS, P. S. "Ciência e tecnologia de argilas". 2a ed., Editora Edgard Blücher Ltda, v.1 e v.3, São Paulo, 1992.

[13] MONTICELli, O., BOTTINO, A., SCANDALE, I., et al., "Preparation and properties of polysulfoneclay composite membranes", Journal of Applied Polymer Science, v. 103, n. 6, pp. 3637-3644, Mar. 2007.

[14] ANADÃO, P., SATO, L. F., WIEBECK, H., DÍAZ, F. R. V. "Montmorillonite as a comonent of polysulfone nanocomposite membranes”, Applied Clay Science. v. 48, n. 1-2, pp. 127-132, Mar. 2010.

[15] ANADÃO, P., WIEBECK, H., DÍAZ, F. R.V., "Panorama da pesquisa acadêmica brasileira em nanocompósitos polímero/argila e tendências para o futuro", Polímeros. v. 21, n. 5, pp. 443-452, Dez. 2011.

[16] SUMMERS, G. J., NDAWUNI, M. P., SUMMERS, C. A. "Dipyridyl functionalized polysulfones for membrane production”, Journal of Membrane Science. v. 226, n. 1-2, pp. 21-33, Dez. 2003.

[17] FAN, Z., WANG, Z., SUN, N., et al., "Performance impovement of polysulfone ultrafiltration membrane by blending with polyaniline nanofibers", Journal of Membrane Science, v. 320, n. 1-2, pp. 363371, Jul. 2008.

[18] MEDEIROS, K. M., KOJUCH, L. R., ARAÚJO, E. M., et al., "membranas obtidas de nanocompósitos pelos métodos de intercalação por fusão e solução". Nanocompósitos poliméricos - pesquisas na UFCG com argilas bentoníticas. $1^{\text {a }}$ Edição - Campina Grande: Edufcg, v. 1, pp. 151-168, 2012.

[19] ANADÃO, P., SATO, L. F., MONTES, R. R., et al., "Polysulphone/montmorillonite nanocomposite membranes: effect of clay addition and polysulphone molecular weight on the membrane properties", Journal of Membrane Science. v. 455, pp. 187-199, Abr. 2014.

[20] BellinCANTA, T., POLETTO, P., THÜMER, M. B., et al., "Preparação e caracterização de membranas poliméricas a partir da blenda polisulfona/poliuretano”, Polímeros. v. 21, n. 3, pp. 229-232, Jul. 2011.

[21] WEI, X., WANG, Z., WANG, J., et al., "A novel method of surface modification to polysulfone ultrafiltration membrane by preadsorption of citric acid or sodium bisulfite", Membrane Water Treatment. v. 3, n. 1, pp. 35-49, Jan. 2012.

[22] YANG, Y., ZHANG, H., WANG, P., et al., "The Influence of nano-sizer tio $_{2}$ fillers on the morphologies and properties of PSF of membrane”, Journal of Membrane Science. v. 288, n. 1-2, pp. 231-238, Fev. 2007. 
[23] ASTM - “ASTM E 96/E 96M-05 - Standard test methods for water vapor transmission of materials", Philadelphia, 2005.

[24] SHARMA, N., PURKAIT, M. K. "Impact of synthesized amino alcohol plasticizer on the morphology and hydrophilicity of polysulfone ultrafiltration", Journal of Membrane Science. v. 522, pp. 202-215, Jan. 2017.

[25] MENEZES, R. R.; ÁVILA JÚNIOR, M. M., SANTANA, L. N. L., et al., "Comportamento de expansão de argilas bentoníticas organofílicas do estado da Paraíba”, Cerâmica. v. 54, n. 330, pp. 152-159, Jun. 2008.

[26] NÓBREGA, K. C., WANDERLEY, A. S. D., LEITE, A. M. D., et al., "Obtenção e caracterização de argilas organofílicas visando à aplicação em nanocompósitos poliméricos”, Revista Eletrônica de Materiais e Processos. v. 6, n. 2, pp. 84-90, 2011.

[27] PEREIRA, J. M. J. "Produção de monoglicerídeos através de catalisadores de argila", Tese de M.Sc., Universidade da Madeira, Funchal, Portugal, 2014.

[28] SANTOS, T. "Preparação e caracterização de membranas compósitas polisulfona/material celulósico como barreira seletiva", Dissertação de M.Sc, Universidade de Caxias do Sul, Caxias do Sul, Rio Grande do Sul, 2011.

[29] MUSHTAQ, A., MUKHTAR, H. B., SHARIFF, A. M. "FTIR study of enhanced polymeric blend membrane with amines", Research Journal of Applied Sciences, Engineering and Technology, v. 7, n. 9, pp. 1811-1820, Mar. 2014.

[30] THIRÉ, R. M. S. M., SIMÃO, R A., ARAÚJO, P. J. G., et al., "Redução da hidrofilicidade de filmes biodegradáveis à base de amido por meio de polimerização por plasma", Polímeros: Ciência e Tecnologia. v. 14, n. 1, pp. 57-62, Mar. 2004.

[31] PICARD, E., GÉRARD, J. F., ESPUCHE, E. "Water transport properties of polyamide 6 based nanocomposites prepared by melt blending: on the importance of the clay dispersion state on the water transport properties at high water activity”, Journal of Membrane Science. v. 313, p. 284-295, Abr. 2008.

[32] RAY, S. S., OKAMOTO M. "Polymer/layered silicate nanocomposites: a review from preparation to processing", Progress in Polymer Science. v. 28, n. 11, pp. 1539-1641, Nov. 2003.

[33] PICARD, E., VERMOGEN, A., GÉRARD, J. F., et al., "Barrier Properties of Nylon 6-Montmorillonite Nanocomposite Membranes Prepared by Melt Lending: Influence of the Clay Content and Dispersion State. Consequences on Modeling”, Journal of Membrane Science. v. 292, p. 133-144, Abr. 2007. 